\title{
Helicobacter pylori Infection and Immunity
}




\section{INFECTIOUS AGENTS AND PATHOGENESIS}

Series Editors: Mauro Bendinelli, University of Pisa

Herman Friedman, University of South Florida

College of Medicine

Recent volumes in this series:

DNA TUMOR VIRUSES

Oncogenic Mechanisms

Edited by Giuseppe Barbanti-Brodano, Mauro Bendinelli, and Herman Friedman

ENTERIC INFECTIONS AND IMMUNITY

Edited by Lois J. Paradise, Mauro Bendinelli, and Herman Friedman

HELICOBACTER PYLORI INFECTION AND IMMUNITY

Edited by Yoshimasa Yamamoto, Herman Friedman, and Paul S. Hoffman

HERPESVIRUSES AND IMMUNITY

Edited by Peter G. Medveczky, Herman Friedman, and Mauro Bendinelli

HUMAN RETROVIRAL INFECTIONS

Immunological and Therapeutic Control

Edited by Kenneth E. Ugen, Mauro Bendinelli, and Herman Friedman

MICROORGANISMS AND AUTOIMMUNE DISEASES

Edited by Herman Friedman, Noel R. Rose, and Mauro Bendinelli

OPPORTUNISTIC INTRACELLULAR BACTERIA AND IMMUNITY

Edited by Lois J. Paradise, Herman Friedman, and Mauro Bendinelli

PSEUDOMONAS AERUGINOSA AS AN OPPORTUNISTIC PATHOGEN

Edited by Mario Campa, Mauro Bendinelli, and Herman Friedman

PULMONARY INFECTIONS AND IMMUNITY

Edited by Herman Chmel, Mauro Bendinelli, and Herman Friedman

\section{RAPID DETECTION OF INFECTIOUS AGENTS}

Edited by Steven Specter, Mauro Bendinelli, and Herman Friedman

RICKETTSIAL INFECTION AND IMMUNITY

Edited by Burt Anderson, Herman Friedman, and Mauro Bendinelli

\section{STAPHYLOCOCCUS AUREUS INFECTION AND DISEASE}

Edited by Allen L. Honeyman, Herman Friedman, and Mauro Bendinelli

A Continuation Order Plan is available for this series. A continuation order will bring delivery of each new volume immediately upon publication. Volumes are billed only upon actual shipment. For further information please contact the publisher. 


\section{Helicobacter pylori Infection and Immunity}

Edited by

Yoshimasa Yamamoto

University of South Florida College of Medicine Tampa, Florida

\section{Herman Friedman}

University of South Florida College of Medicine

Tampa, Florida

and

\section{Paul S. Hoffman}

Dalhousie University

Halifax, Nova Scotia, Canada

Springer Science+Business Media, LLC 
Library of Congress Cataloging-in-Publication Data

Helicobacter pylori infection and immunity/edited by Yoshimasa Yamamoto, Herman Friedman and Paul Hoffman.

p. ; cm. - (Infectious agents and pathogenesis)

Includes bibliographical references and index.

ISBN 978-1-4613-5192-4 ISBN 978-1-4615-0681-2 (eBook)

DOI 10.1007/978-1-4615-0681-2

1. Helicobacter pylori infections. 2. Helicobacter pylori infections-Immunological aspects. I. Yamamoto, Yoshimasa II. Friedman, Herman, 1931- III. Hoffman, Paul S. IV. Series.

[DNLM: 1. Helicobacter pylori-immunology. 2. Gastritis-parasitology. 3.

Helicobacter Infections-drug therapy. 4. Helicobacter Infections-immunology. 5.

Helicobacter Infections-pathology. 6. Helicobacter pylori-pathogenicity. QW 154 H4572 2001]

QR201.H44 H463 2002

$616^{\prime} .01423-\mathrm{dc} 21$

ISBN 978-1-4613-5192-4

(C)2002 Springer Science+Business Media New York

Originally published by Kluwer Academic/Plenum Publishers, New York in 2002

Softcover reprint of the hardcover 1st edition 2002

http://www.wkap.nl/

$\begin{array}{llllllllll}10 & 9 & 8 & 7 & 6 & 5 & 4 & 3 & 2 & 1\end{array}$

A C.I.P. record for this book is available from the Library of Congress

All rights reserved

No part of this book may be reproduced, stored in a retrieval system, or transmitted in any form or by any means, electronic, mechanical, photocopying, microfilming, recording, or otherwise, without written permission from the Publisher. 


\section{Contributors}

BEN J. APPELMELK - Department of Medical Microbiology, Vrije Universiteit, Amsterdam, The Netherlands

INGRID L. BERGIN - Division of Comparative Medicine, Massachusetts Institute of Technology, Cambridge, MA 02139

THOMAS G. BLANCHARD - Department of Pediatrics, Division of Pediatric Gastroenterology, Case Western Reserve University School of Medicine and Rainbow Babies and Children's Hospital, Cleveland, $\mathrm{OH}$ 44106

PELAYO CORREA - Pathology, Louisiana State University Health Sciences Center, New Orleans, LA

JEAN E. CRABTREE - Molecular Medicine Unit, St. James University Hospital, Leeds LS9 7TF, United Kingdom

STEVEN J. CZINN - Department of Pediatrics, Division of Pediatric Gastroenterology, Case Western Reserve University School of Medicine and Rainbow Babies and Children's Hospital, Cleveland, OH 44106

STANLEY FALKOW - Department of Microbiology and Immunology, Stanford University, Stanford, CA

GERHARD FALLER - Department of Pathology, University Erlangen, Erlangen, Germany

JAMES G. FOX - Division of Comparative Medicine, Massachusetts Institute of Technology, Cambridge, MA 02139

YOSHIHIRO FUKUDA - Internal Medicine, Hyogo College of Medicine, Nishinomiya, Hyogo 663-8501, Japan 
BENJAMIN D. GOLD - Division of Pediatric Gastroenterology and Nutrition, Department of Pediatrics, Emory University School of Medicine, Children's Healthcare of Atlanta at Egleston Children's Hospital, Foodborne and Diarrheal Disease Branch, Division of Bacterial and Mycotic Diseases, National Center for Infectious Diseases, Centers for Disease Control and Prevention, Atlanta, GA

PAUL S. HOFFMAN - Departments of Microbiology and Immunology and Medicine, Division of Infectious Diseases, Dalhousie University, Halifax, Nova Scotia B3H4H7, Canada

JIA-QING HUANG - Division of Gastroenterology, Department of Medicine, McMaster University Medical Center, Hamilton, Ont., Canada L8N $3 Z 5$

RICHARD H. HUNT - Division of Gastroenterology, Department of Medicine, McMaster University Medical Center, Hamilton, Ont., Canada L8N 3 Z5

SHIGERU KAMIYA - Department of Microbiology, Kyorin University School of Medicine, Mitaka, Tokyo 181-8611, Japan

FRANCIS MEGRAUD - Laboratoire de Bacteriologie, Hopital Pellegrin, Bordeaux, France

TAMARA MATYSIAK - INSERM E9925, Faculte Necker-Enfants Malades, Paris, France

STEVEN F. MOSS - Department of Medicine, St. Luke's Roosevelt Hospital Center/Columbia University, New York, NY 10025

KAREN M. OTTERMAN • Department of Biology and Environmental Toxicology, University of California at Santa Cruz, Santa Cruz, CA

TAKASHI SAKAGAMI - Internal Medicine, Hyogo College of Medicine, Nishinomiya, Hyogo 663-8501, Japan

NINA R. SALAMA - Department of Microbiology and Immunology, Stanford University, Stanford, CA

HIROKO SASHIO - Institute Advanced Medical Sciences, Laboratory Hereditary Tumor, Hyogo College of Medicine, Hyogo 663-8501, Japan

YUKIO SAWADA - Internal Medicine, Hyogo College of Medicine, Nishinomiya, Hyogo 663-8501, Japan

PHILIP M. SHERMAN - Division of Pediatric Gastroenterology and Nutrition, The Hospital for Sick Children, Department of Pediatrics, University of Toronto, Toronto, Ont., Canada 
TAKASHI SHIMOYAMA - Internal Medicine, Hyogo College of Medicine, Nishinomiya, Hyogo 663-8501, Japan

EMILIA MIA SORDILLO - Department of Pathology and Laboratory Medicine, and Department of Medicine, St. Luke's Roosevelt Hospital Center/Columbia University, New York, NY 10025

KAZUO TAMURA - Institute Advanced Medical Sciences, Laboratory Hereditary Tumor, Hyogo College of Medicine, Hyogo 663-8501, Japan

NORITOSHI TANIDA - Internal Medicine, Hyogo College of Medicine, Nishinomiya, Hyogo 663-8501, Japan

DIANE E. TAYLOR - Department of Medical Microbiology and Immunology, University of Alberta, Edmonton, Alberta, Canada T6G 2H7

CHRISTINA M. J. E. VANDENBROUCKE-GRAULS - Department of Medical Microbiology, Vrije Universiteit, Amsterdam, The Netherlands

GE WANG - Department of Medical Microbiology and Immunology, University of Alberta, Edmonton, Alberta, Canada T6G 2H7

HIROYUKI YAMAGUCHI - Department of Microbiology, Kyorin University School of Medicine, Mitaka, Tokyo 181-8611, Japan

NORIYASU YAMAMOTO - Internal Medicine, Hyogo College of Medicine, Nishinomiya, Hyogo 663-8501, Japan

YOSHIMASA YAMAMOTO - Department of Medical Microbiology and Immunology, University of South Florida College of Medicine, Tampa, FL 33612 


\section{Preface to the Series}

The mechanisms of disease production by infectious agents are presently the focus of an unprecedented flowering of studies. The field has undoubtedly received impetus from the considerable advances recently made in the understanding of the structure, biochemistry, and biology of viruses, bacteria, fungi, and other parasites. Another contributing factor is our improved knowledge of immune responses and other adaptive or constitutive mechanisms by which hosts react to infection. Furthermore, recombinant DNA technology, monoclonal antibodies, and other newer methodologies have provided the technical tools for examining questions previously considered too complex to be successfully tackled. The most important incentive of all is probably the regenerated idea that infection might be the initiating event in many clinical entities presently classified as idiopathic or of uncertain origin.

Infectious pathogenesis research holds great promise. As more information is uncovered, it is becoming increasingly apparent that our present knowledge of the pathogenic potential of infectious agents is often limited to the most noticeable effects, which sometimes represent only the tip of the iceberg. For example, it is now well appreciated that pathologic processes caused by infectious agents may emerge clinically after an incubation of decades and may result from genetic, immunologic, and other indirect routes more than from the infecting agent in itself. Thus, there is a general expectation that continued investigation will lead to the isolation of new agents of infection, the identification of hitherto unsuspected etiologic correlations, and, eventually, more effective approaches to prevention and therapy.

Studies on the mechanisms of disease caused by infectious agents demand a breadth of understanding across many specialized areas, as well as much cooperation between clinicians and experimentalists. The series Infectious Agents and Pathogenesis is intended not only to document the state of the art in this fascinating and challenging field but also to help lay bridges among diverse areas and people.

M. Bendinelli

H. Friedman 


\section{Preface}

The discovery and concept that Helicobacter pylori is associated with gastric disease including gastric cancer which is one of the most common and frequently lethal forms of malignancy, heralded a new and rapidly expanding field recognizing the emergence of many new pathogens and disease syndromes in clinical medicine, as well as basic infectious disease research. There is now an extensive and widely known literature of how $H$. pylori is involved in a wide variety of disease syndromes. As summarized in the introductory chapter of this volume, many major advances have been made in diagnosis, both serologic and endoscopic in time of the involvement of this organism in patients with upper GI ailments as well as its presence in those who are not clinically ill. The Introduction describes the rapid development of understanding the role of this organism in disease.

The basic bacteriology of $H$. pylori is then described in the second chapter. Diagnostic tests for detecting $H$. pylori infection is then highlighted, as well as the role of such infection in gastric cancer. Current knowledge concerning risk factors and peptic ulcer pathology associated with $H$. pylori is then described. Newer information concerning therapy of $H$. pylori infection and colonization is described in a subsequent chapter as well as one concerning the effects of antibiotics on $H$. pylori infection. The extensive literature on natural substances with anti- $H$. pylori activity is then described, followed by a chapter dealing with newer knowledge concerning how this microorganism binds to gastric cells. The involvement of $\mathrm{H}$. pylori in autoimmune diseases is then described as well as the pathogenesis of how this organism is related to diseases. The effects of toxins by the organism on host cells as well as development of animal models for $\mathrm{H}$. pylori infection studies is described, followed by a review of development of a gerbil model for $H$. pylori infection. New information concerning development of a vaccine against Helicobacter is also presented in the final chapter.

It is anticipated by the editors as well as the authors of the individual chapters, who represent cutting edge laboratories from this country as well as many other countries, that this book will provide useful and valuable information 
concerning the current status of immunologic, microbiologic, as well as therapeutic prevention studies against the important human pathogen $H$. pylori. The Editors thank Ms. Ilona Friedman for excellent editorial assistance in coordinating and assisting in the preparation of the manuscripts for this volume in this series.

Paul Hoffman

Yoshimasa Yamamoto

Herman Friedman 


\section{Contents}

Introduction and Perspectives $\ldots \ldots \ldots \ldots \ldots \ldots \ldots \ldots \ldots \ldots \ldots \ldots$

PAUL S. HOFFMAN

1. The Bacteriology of Helicobacter pylori

PAUL S. HOFFMAN

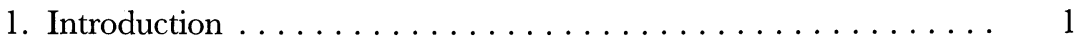

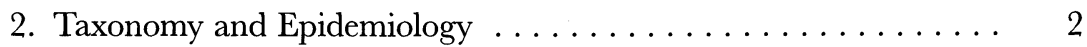

2.1. Human Isolates . . . . . . . . . . . . . . . . . . 2

2.2. Related Species of Helicobacter $\ldots \ldots \ldots \ldots \ldots \ldots \ldots$

3. Life in the Gastric Mucosa ................... 3

4. Survival in Acid Environments $\ldots \ldots \ldots \ldots \ldots \ldots \ldots \ldots$

5. Role of Urease in $\mathrm{pH}$ Stasis $\ldots \ldots \ldots \ldots \ldots \ldots \ldots \ldots . \ldots \ldots$

6. Acid Shock and Other Stresses $\ldots \ldots \ldots \ldots \ldots \ldots \ldots \ldots$

7. Motility and Chemotaxis .................. 7

8. Inflammation and Nutrient Acquisition $\ldots \ldots \ldots \ldots \ldots \ldots$

9. Metabolic Capabilities of $H$. pylori ............... 8

10. Respiration and Energy Production .............. 12

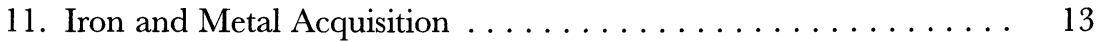

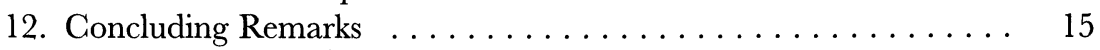

References ........................ 15

\section{Diagnosis of Helicobacter pylori Infection}

FRANCIS MÉGRAUD AND TAMARA MATYSIAK

1. Introduction . . . . . . . . . . . . . . . . . . . 19

2. Tests Performed Directly by the Physician $\ldots \ldots \ldots \ldots \ldots \ldots \quad 20$ 
2.1. Tests Performed by the Endoscopist $\ldots \ldots \ldots \ldots \ldots \ldots .20$

3. Tests Performed by Any Physician $\ldots \ldots \ldots \ldots \ldots \ldots \ldots \ldots 20$

4. Tests for Which A Laboratory Is Needed . . . . . . . . . . . . 21

4.1. Standard Bacteriological Tests . . . . . . . . . . . . . 21

4.2. Histological Detection . . . . . . . . . . . . . . . . . . 23

4.3. Polymerase Chain Reaction .................... 23

4.4. Tests Performed by Any Physician . . . . . . . . . . . . 24

4.5. Antigen Stool Test ..................... 25

4.6. Detection of Specific Antibodies in Serum . . . . . . . . . 26

4.7. Detection of Specific Antibodies in Saliva ............ 28

4.8. Detection of Specific Antibodies in Urine . . . . . . . . . 28

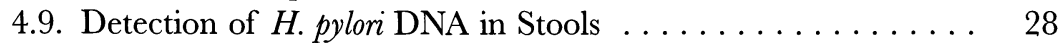

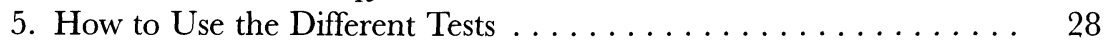

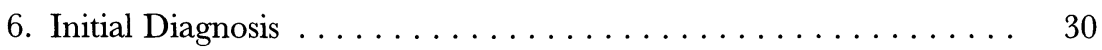

7. Post-Treatment Follow-Up $\ldots \ldots \ldots \ldots \ldots \ldots \ldots \ldots \ldots \ldots \ldots$

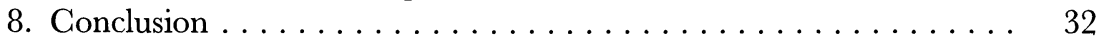

References ......................... 32

\section{Helicobacter pylori Infection and Gastric Gancer} PELAYO CORREA

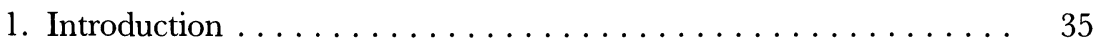

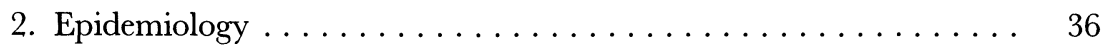

3. The Gastric Precancerous Process $\ldots \ldots \ldots \ldots \ldots \ldots \ldots . \ldots \ldots$

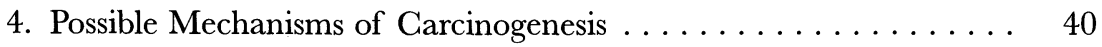

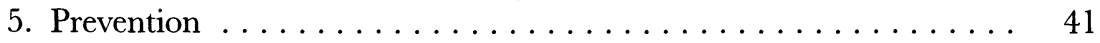

6. Malt Lymphoma (Maltoma) . . . . . . . . . . . . . . . 44

7. Epilogue: A New Paradigm ..................... 45

References ........................ 46

\section{Risk Factors and Peptic Ulcer Pathology}

BENJMAIN D. GOLD AND PHILIP M. SHERMAN

1. Introduction . . . . . . . . . . . . . . . . . . . . . 49

2. Pathobiology of $H$. pylori Infection-Induced

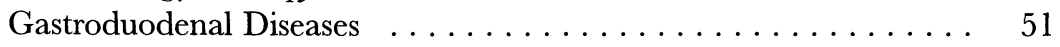

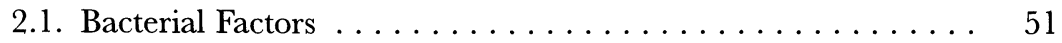

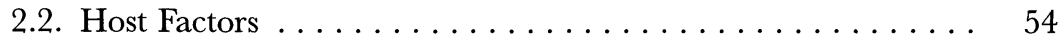


3. Pathologic Sequelae ...................... 58

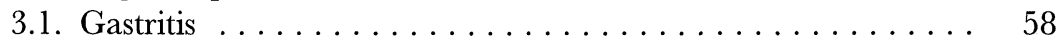

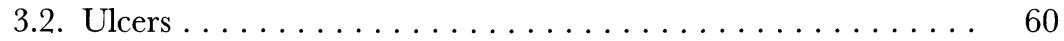

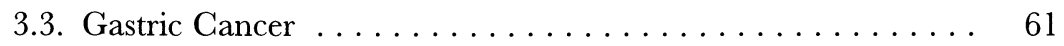

3.4. Gastric Lymphomas . . . . . . . . . . . . . . . . . 61

4. Summary and Future Directions . . . . . . . . . . . . . 63

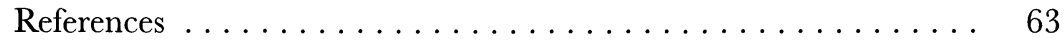

\section{Helicobacter pylori Eradication Therapy}

JIA-QING HUANG AND RICHARD H. HUNT

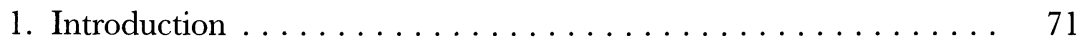

2. Treatment-Related Factors $\ldots \ldots \ldots \ldots \ldots \ldots \ldots \ldots \ldots$

3. Dose, Dose Frequency and Treatment Duration . . . . . . . . . 73

4. Patient-Related Factors . . . . . . . . . . . . . . . . . . . 74

5. Bacterial Resistance ... . . . . . . . . . . . . . . . . . 74

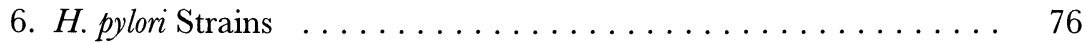

7. Newer Treatment Regimens $\ldots \ldots \ldots \ldots \ldots \ldots$

8. Furazolidone-Containing Regimens . . . . . . . . . . . . 77

9. Bismuth Based Single Capsule Triple Therapy . . . . . . . . . . . 78

10. Management of Treatment Failures . . . . . . . . . . . . 79

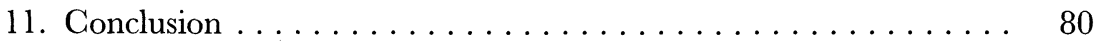

References ........................ 81

\section{Mechanisms of Antibiotic Resistance in Helicobacter pylori}

GE WANG AND DIANE E. TAYLOR

1. Introduction . . . . . . . . . . . . . . . . . . . . 87

2. Susceptibility and Resistance ................. 87

3. Clinically Relevant Resistance . . . . . . . . . . . . . . . . . 89

4. Clarithromycin Resistance . . . . . . . . . . . . . . . . . . . . . 89

5. Metronidazole Resistance . . . . . . . . . . . . . . . . . . 92

6. Amoxicillin Resistance . . . . . . . . . . . . . . . . . 95

7. Ciprofloxacin Resistance . . . . . . . . . . . . . . . 96

8. Rifampicin Resistance . . . . . . . . . . . . . . . . . 96

9. Tetracycline Resistance . . . . . . . . . . . . . . . . . . . . 97

10. Genetic Pathways . . . . . . . . . . . . . . . . . . . . 97

11. Gene Transfer ......................... 98 


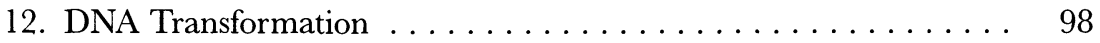

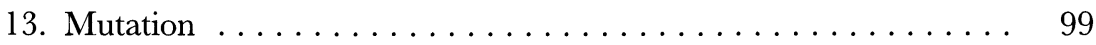

References .......................... 102

\section{Anti-Helicobacter pylori Activity of Natural Substances} YOSHIMASA YAMAMOTO

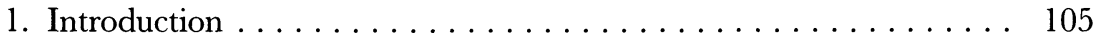

2. Medicinal Plants . . . . . . . . . . . . . . . . . . . . . . 106

3. Nutritional Agents $\ldots \ldots \ldots \ldots \ldots \ldots \ldots \ldots \ldots \ldots \ldots \ldots$

4. Tea ......................... 110

4.1. Microbiological Effects of Tea ............... 110

4.2. Anti-H. pylori Activity of Tea Catechins . . . . . . . . . 112

4.3. In vivo Activity of Tea Catechins . . . . . . . . . . . . . . 114

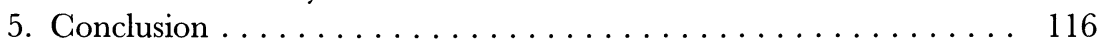

References ........................ 116

\section{Adherence of Helicobacter pylori to Gastric Gell}

\section{SHIGERU KAMIYA AND HIROYUKI YAMAGUCHI}

1. Adherence Properties of $H$. pylori to Gastric Cell ......... 121

1.1. Specificity of Adherence of $H$. pylori ............ 121

1.2. Adherence of Spiral and Coccoid Forms of H. pylori ....... 121

1.3. Attaching and Effacement by Adherence of H. pylori ....... 122

2. Adhesin of H. pylori and its Receptor ............... 122

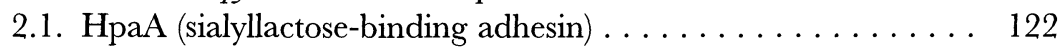

2.2. Adhesin Recognizing Phosphatidylethanolamine ...... . . . 124

2.3. BabA Protein Recognizing Lewis ${ }^{\mathrm{b}}$ Antigen . . . . . . . . . . . 125

2.4. Adhesin Recognizing Sulfatide ................ 126

2.5. Adhesin Recognizing Extracellular Matrix Components . . . . 127

2.6. Heat Shock Protein (HSP) _ . . . . . . . . . . . . . . . . . 128

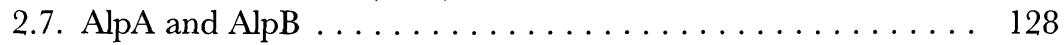

2.8. HopZ . . . . . . . . . . . . . . . . . . . . 129

3. Biological and Pathological Significance of Adherence of H. pylori to Gastric Gell ........................... 129

3.1. Induction of Secretion of Various Cytokines from Gastric Cells . . . . . . . . . . . . . . . . . . . . . . . 129

3.2. iceA (induced by contact with epithelium) $\ldots \ldots \ldots \ldots \ldots$ 
3.3. Attachment-Related Pathology and Induction of Auto-Antibodies to Lewis ${ }^{\mathrm{b}}$ Carbohydrated Epitope . . . . . . . 130

3.4. Induction of Tyrosine Phosphorylation of Host Cell Proteins ........................ 131

References .......................... 132

\section{Helicobacter pylori, Molecular Mimicry and Autoimmunity} BEN J. APPELMELK, GERHARD FALLER, AND CHRISTINA M. J. E. VANDENBROUCKE-GRAULS

1. Introduction . . . . . . . . . . . . . . . . . . . . . . . . 135

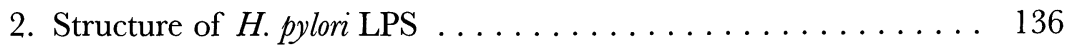

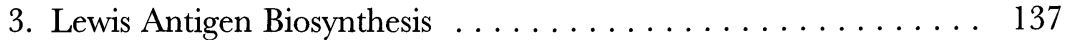

4. Phase Variation . . . . . . . . . . . . . . . . . . 138

5. Biological Role of $H$. pylori LPS Lewis Antigens . . . . . . . . . 141

5.1. H. pylori Mimicry is Pathogenic . . . . . . . . . . 141

5.2. Lewis Antigen Mimicry Provides Immune Escape . . . . . . 142

5.3. H. pylori Lewis Antigens Mediate Adhesion and

Colonization ....................... 143

6. Helicobacter pylori and Autoimmunity . . . . . . . . . . . . 144

6.1. From A to B: Autoimmune Gastritis and the Possible

Pathogenic Role of $H$. pylori Infection . . . . . . . . . . . 144

6.2. From B to A: H. pylori Gastritis and the Possible Pathogenic

Role of Antigastric Autoimmune Reactions . . . . . . . . 145

7. Clinical Relevance of Anticanalicular Autoantibodies in

H. pylori Gastritis . . . . . . . . . . . . . . . . . . . 146

8. The Gastric $\mathrm{H}^{+}, \mathrm{K}^{+}$-ATPase As Autoantigen in Atrophic

H. pylori Gastritis . . . . . . . . . . . . . . . . . 146

9. A Model for the Pathogenesis of $H$. pylori Associated Antigastric Autoimmunity ........................ 147

10. Questions for Future Research . . . . . . . . . . . . . . . . . . 147

References ...................... 148

10. Apoptosis and the Pathogenesis of Helicobacter pyloriRelated Disease

EMILIA MIA SORDILLO AND STEVEN F. MOSS

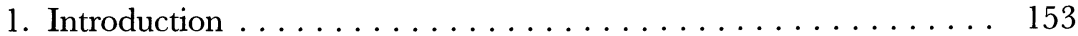

2. Evidence of Apoptosis in Human Infection with H. pylori . . . . . 154 


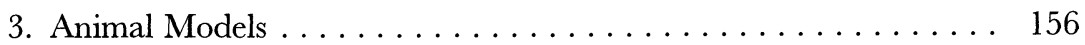

4. Mechanisms of Apoptosis Associated with H. pylori Infection . . . 158

4.1. Inflammation, IL-8 and Epithelial Cell Apoptosis . . . . . . 158

4.2. Are Intact, Viable Bacteria Required for Induction of Apoptosis? . . . . . . . . . . . . . . . . . . 158

4.3. The Type IV Secretion System in H. pylori Encoded by

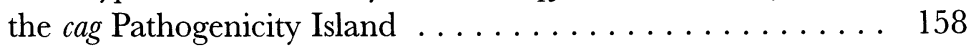

4.4. VacA Cytotoxin and Apoptosis . . . . . . . . . . . . . 159

4.5. Signaling Molecules and Signal Transduction and Apoptosis ....................... 160

5. Alterations in the Cell Cycle and Apoptosis Resistance ....... . 161

6. Adherence and Apoptosis . . . . . . . . . . . . . . . . . 162

7. Apoptosis and Pathogenesis of Ulcers and Cancer ......... 164

8. Is a Deficiency in Apoptosis Responsible for the Development of Cancer? . . . . . . . . . . . . . . . . . . . . . 166

9. Conclusions and Speculations $\ldots \ldots \ldots \ldots \ldots \ldots \ldots \ldots \ldots$

References ............................. 167

\title{
11. Toxins, Travels and Tropisms: H. pylori and Host Gells
}

\author{
NINA R. SALAMA, STANLEY FALKOW, \\ AND KAREN M. OTTEMANN
}

1. Introduction . . . . . . . . . . . . . . . . . . . 173

2. Adherence .......................... 174

2.1. In the Real Stomach World .................. 174

3. The Molecular Basis for H. pylori Adherence ........... 174

4. Adherence to the Lewis B. Antigen ............... 176

5. Beyond Le ${ }^{b}$ to Several Alleged Adhesins . . . . . . . . . . . 177

6. What Does Adherence Do for H. pylori Anyway? . . . . . . . . 178

7. The Vacuolating Cytotoxin, VacA . . . . . . . . . . . . 179

8. Primary Sequence and Sequence Variability of $v a c A \ldots \ldots \ldots 179$

9. Tertiary Structure of the VacA Protein ............. 182

10. The Relationship between Structure and Function ........ 183

11. Characterization of Vacuoles . . . . . . . . . . . . . . 183

11.1. The Role of ATPases . . . . . . . . . . . . . . . 183

11.2. From Where Do the Vauole Membranes Originate? . . . . 184

11.3. What's on and inside VacA Vacuoles? . . . . . . . . . 186

11.4. Mechanisms of VacA Action ............. 186

11.5. How Does VacA Get inside Gells and Where Does it

Localize? . . . . . . . . . . . . . . . . . . . . . . . . . . 187 
11.6. Pore Forming Activity . . . . . . . . . . . . . . . 187

11.7. Antigen Processing . . . . . . . . . . . . . . . . . 189

11.8. Role of VacA in Virulence . . . . . . . . . . . . . . . . 189

12. H. pylori Alters Cell Proliferation ............... 190

13. How H. pylori Affects Cell Shape and Motility .......... 192

14. Conclusion ........................... 193

References ........................ 195

\title{
12. Role of Gytokines in Helicobacter pylori Infection
}

\author{
JEAN E. CRABTREE
}

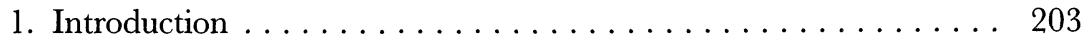

2. Cytokines and Innate Host Responses . . . . . . . . . . . . 204

3. Cytokines and Antigen Specific Immune Responses . . . . . . . . 206

4. Cytokine Modulation of Gastric Physiological Responses . . . . . 208

5. Cytokines and Protective Immunity . . . . . . . . . . . . . . 208

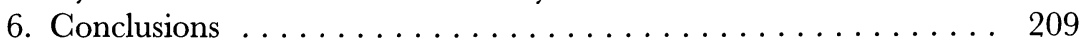

References .............................. 209

\section{Animal Models for Helicobacter pylori}

INGRID L. BERGIN AND JAMES G. FOX

1. Introduction . . . . . . . . . . . . . . . . . . . . 215

2. Ferrets: H. mustelae ................... 216

2.1. Comparison between Human and Ferret Gastric

Helicobacter Infections . . . . . . . . . . . . . . . . 216

3. Utility of the Ferret Gastric Helicobacter Model . . . . . . . . 218

4. Cats: Gastric Helicobacter-like Organisms, H. felis, H. pylori . . . . . 219

5. Comparison between Human and Feline Gastric Helicobacter Infections . . . . . . . . . . . . . . . . . . . . . . 222

6. Utility of the Feline Gastric Helicobacter Model . . . . . . . . 222

7. Swine: GHLOs, H. pylori . . . . . . . . . . . . . . . . 223

8. Comparison between Human and Procine Gastric Helicobacter Infections . . . . . . . . . . . . . . . . . . . . . 223

9. Utility of the Swine Gastric Helicobacter Model . . . . . . . . . 224

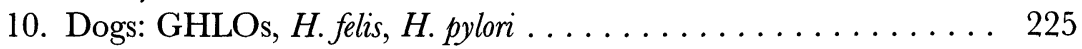


10.1. Gastric Helicobacter Infections of Dogs . . . . . . . . . . . 225

10.2. Comparison between Human and Canine Helicobacter

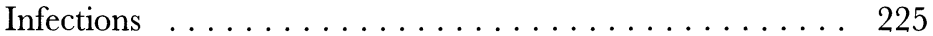

10.3. Utility of the Canine Model . . . . . . . . . . . . . 226

11. Non-Human Primates: GHLOs, H. felis, H. pylori . . . . . . . . 226

11.1. Natural Infections . . . . . . . . . . . . . . . . . . 226

11.2. Experimental Infections . . . . . . . . . . . . . . . 227

11.3. Comparison of Pathology between NHPs and Humans . . . 228

11.4. Utility of the NHP Model . . . . . . . . . . . . . . . 228

12. Rats, Guinea Pigs, Gerbils . . . . . . . . . . . . . . . . . . 229

12.1. Rats: H. felis, GHLOs, H. pylori . . . . . . . . . . . . 229

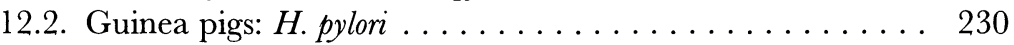

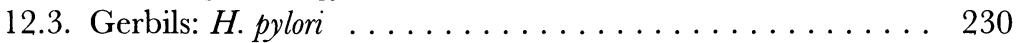

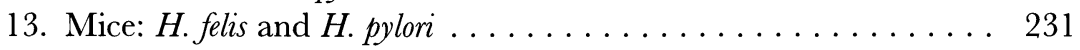

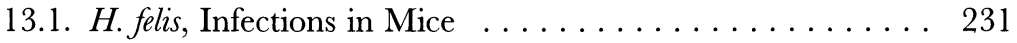

13.2. Inbred Strains Susceptible to Gastritis . . . . . . . . . . . 231

13.3. Inbred Strains Resistant to Gastritis . . . . . . . . . . . . . 232

13.4. H. pylori Infections in Mice . . . . . . . . . . . . 233

13.5. Early Studies with Clinical Isolates . . . . . . . . . . . . 233

13.6. Standardized Strain for Mouse Models: The Sidney

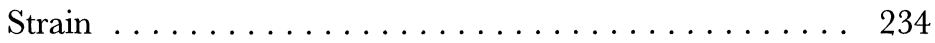

14. Utility of $H$. pylori and $H$. felis Mouse Models . . . . . . . . . 235

14.1. Role of Thl and Th2 Responses . . . . . . . . . . . 235

14.2. Role of Cytokines . . . . . . . . . . . . . . . . 236

15. Immunization Trials $\ldots \ldots \ldots \ldots \ldots \ldots \ldots \ldots \ldots \ldots$

16. Therapeutic Agents . . . . . . . . . . . . . . . . . . . . 240

17. Disease Pathogenesis . . . . . . . . . . . . . . . . . . . . 240

18. Conclusions and Future Prospects . . . . . . . . . . . 241

References .......................... 242

\section{Mongolian Gerbils Model}

TAKASHI SHIMOYAMA, TAKASHI SAKAGAMI,

NORIYASU YAMAMOTO, YUKIO SAWADA,

YOSHIHIRO FUKUDA, NORITOSHI TANIDA,

HIROKO SASHIO, AND KAZUO TAMURA

1. Introduction . . . . . . . . . . . . . . . . . . . . 253

2. Mongolian Gerbils . . . . . . . . . . . . . . . . . . . 254

3. Gastritis and Gastric Ulcer . . . . . . . . . . . . . . . . 254 
4. Gastric Cancer . . . . . . . . . . . . . . . . . . . . 256

5. Summary . . . . . . . . . . . . . . . . . . . 259

References ....................... 260

\section{Vaccine Development}

\section{THOMAS G. BLANCHARD AND STEVEN J. CZINN}

1. Need for a $H$. pylori Vaccine . . . . . . . . . . . . . . . 263

2. Early $H$. pylori Vaccine Success Stories . . . . . . . . . . . . 265

3. Translation to $H$. pylori Models and Humans . . . . . . . . . 267

4. Mechanisms of Protection . . . . . . . . . . . . . . . . 268

5. Optimizing Subunit Vaccines $\ldots \ldots \ldots \ldots \ldots 271$

6. Developing An Effective Mucosal Adjuvant or Delivery System . . 271

7. Alternative Strategies to Mucosal Adjuvants . . . . . . . . . . . . 273

8. Mining Alternative Routes of Vaccine Delivery . . . . . . . . . . 274

References ..................... 276

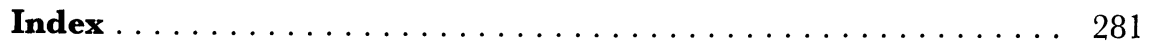




\section{Introduction and Perspectives}

\section{PAUL HOFFMAN}

The latter quarter of the $20^{\text {th }}$ century saw the emergence of many new pathogens or disease syndromes, including Legionnaires' disease, toxic shock syndrome, Lyme disease, and AIDS; but perhaps the most surprising finding was that a microbe (Helicobacter pylor) was associated with duodenal and gastric ulcers. Prior to the findings of Warren and Marshall in $1983^{1}$ and until general acceptance of the finding by the 90 's, most believed that ulcers were due to life style, behavior type, or diet. Interestingly, the spiral-shaped microaerobic bacteria associated with gastric biopsy material had been previously observed at the beginning of the century, but the association with gastric disease was never established. Helicobacter pylori became the subject of one of the most intensive investigations in the history of medicine as new knowledge revealed that half or more of all people worldwide are infected by this organism and life long infection is a proven risk-factor in development of gastric cancer, one of the most common and frequently lethal of all cancers. The pharmaceutical industry, once the benefactors of billion dollar ulcer treatment therapeutics (Zantac, Tagamet, Tums and Rolaids to mention a few), now focused on development of new antimicrobials for the potentially worldwide market, while others focused on development of diagnostic tools from endoscopic devices to rapid diagnostic kits for singling out those for eradicative therapy. Pharmaceutical companies provided unprecedented levels of financial support to this area, and were a driving force behind many of the new

PAUL HOFFMAN - Department of Microbiology and Immunology, Dalhousie University, Halifax, Nova Scotia B3H 4H7, CANADA.

Helicobacter pylori Infection and Immunity,

Edited by Yamamoto et al., Kluwer Academic/Plenum Publishers, 2002. 
technologies (genomics, bioinformatics and proteomics) that have contributed to characterization of $H$. pylori. Population biology and microbial ecology have also contributed substantially to our understanding of strains and diversity. More recently we have learned that nearly all mammals harbor their own species of Helicobacter $^{2}$ and some are suggesting now that infection might be benign or even beneficial by protecting against development of esophageal reflux and cancer of the esophagus. ${ }^{3}$

Helicobacter pylori often establishes life long infections of the gastric mucosa, a site generally considered as sterile only a few decades ago, which raises many fundamental questions as to how it persists in this niche, how it survives stomach acid, and why the host immune system, while recognizing the presence of infection, seems incapable of mounting an eradicative immune response. Understanding persistence and host immune response is key to vaccine strategies, be it protective or therapeutic. Physiological studies reveal that $H$. pylori is unremarkable in its resistance to acid, ${ }^{4}$ being no more resistant than Escherichia coli. The bacteria produce a powerful urease that is regulated in response to acid, ${ }^{4}$ so that the ammonia and carbonate produced by this enzyme most likely create a microenvironment that is alkaline, something no other studied pathogen seems capable of doing. Further study shows that the densest colonization by $H$. pylori occurs in the antrum (lower portion of the stomach) where conditions are less acidic. As the infection becomes more pronounced, or under conditions where the antrum becomes more alkaline (e.g., acid suppressive therapeutics like proton pump inhibitors and H2-blockers), the motile bacteria migrate up into the cardia (body) of the stomach. Infection with $H$. pylori bacteria is basically in three dimensions, as these bacteria not only can move north and south in the mucosa in response to acid levels, but they are able to move freely up and down in the mucus layer that coats the gastric mucosa and provides a protective barrier against the diffusion of strong acid onto the epithelium. The notion of being "off shore" and therefore out of reach of the macrophages and cells of host immune defense may also play an important role in survival. Finally, mounting evidence suggests that $H$. pylori may control the immune response through mimicry (LPS displaying Lewis antigens) and selective release of inflammatory factors. The balance between promotion of inflammation and immune suppression are a key to persistence and an area where novel therapeutics, perhaps in combination with vaccine strategies, could be directed.

The discovery of and extreme interest in Helicobacter, a relative of Campylobacter (bacterial pathogens of the lower GI tract), fortunately coincided with the beginning of the genomics era, and is the beneficiary of two completely sequenced genomes of $H$. pylori. ${ }^{5,6}$ The results reveal a small genome (1.67 megabases) containing some 1553 genes encoding around 1,300 proteins. Despite possessing a limited number of genes, $H$. pylori displays auxotropy for only a few amino acids and appears to possess most catabolic and anabolic pathways found in bacteria with larger genomes. Recent studies examining essentiality testing 
on a genome scale suggested that there are few redundancies and backups in metabolic pathways and thus the percentage of $H$. pylori genes found essential may be greater than expected for organisms with larger genomes, perhaps opening a door for development of Helicobacter selective therapeutics. ${ }^{7}$ Other caveats from genome gazing is that there are few regulatory genes, particularly two component signal transduction systems, that are so typical of enteric bacteria and many pathogens, perhaps suggesting that other than acid and related stresses, $H$. pylor has little else to worry about in its gastric niche. ${ }^{8,9,10}$

Major interest has focused on genes clustered in a pathogenicity island (PAI) that are associated with strains causing more pathology and gastric manifestations. These CagA positive strains (Cytotoxin associated gene) possess a 40 kilobase region encoding genes with orthologs in the type IV secretion and pathogenesis system of Agrobacterium and Bordetella pertussis to mention a few. ${ }^{11}$ The CagA gene is located at one end of the PAI and serves as a marker for Cag status. Strains lacking the Cag PAI are characterized as less virulent as indicated by colonization at lower microbial densities and producing less inflammation than $\mathrm{Cag}^{+}$strains. However, there is still debate over relative association with ulcers and more severe disease. Genes within the Cag PAI promote secretion of a vaculating cytotoxin protein (VacA) whose gene is located outside of the Cag locus. Recently, studies show that the Cag PAI is also responsible for delivery of the CagA protein into mammalian cells and that this protein exhibits tyrosine phosphatase activity. ${ }^{12}$ Thus these toxins are considered important in the pathogenesis and severity of disease.

New applications of bioinformatics and proteomics have also contributed to expanded knowledge of protein interactions ${ }^{13}$ and assignment of function to many of the $H$. pylori genes whose function is unknown. As more microbial genomes become available and annotated, it is likely that more of the unknown genes will be assigned a biological function. Also anticipated is that selected DNA sequencing from a wide range of strains that are geographically distinct will provide information on genetic diversity of this species. Population biological studies have established genetic differences among European and Asian strains and these warrant further study as the information might be applied to selective therapeutics for strains from a particular region. ${ }^{14}$ Other areas of study that will develop in the future will include study of genes common to microaerophiles such as those common between $H$. pylori and Campylobacter jejuni, but unique from those of other microbes, might be exploited more generally for therapeutics or vaccines applicable to eliminating these organisms not only from man but from fowl (common reservoir for Campylobacter).

Advancements in diagnostics, both serologic, stool antigen test, and invasive (endoscopy) have led to sorting of infected people with upper GI ailments from those who are uninfected. Studies now show that nearly $35 \%$ of the world's population suffers from dyspepsia, but only 5 to $20 \%$ of these individuals are also infected with $H$. pylori. In western societies, even fewer are infected with more 
severe CagA strains and in either case, studies have shown that eradication of $H$. pylori infection may not necessarily resolve dyspeptic symptoms. ${ }^{15}$ Thus, general practitioners tend not to investigate the basis for dyspepsia and often simply treat the symptoms with anti-acids and or acid secretion blockers. The assumption that $H$. pylori infection is rather benign - particularly in western societies where gastric cancer is rare in the first place (10 on the list of cancers in the US for example)seems to justify the practice. Where alarm symptoms are noted, referral to a specialist and further investigation by endoscopy is generally pursued. As mentioned earlier, the worry over cure of $H$. pylori and the subsequent development of gastric esophageal reflux disease (GERD) has raised concerns among physicians and the notion that the only good Helicobacter is a dead one, has been challenged. It is not clear what the future will bring, but given that 75 to $80 \%$ of North Americans are or never were infected with $H$. pylori, needs to be considered in this argument. Are they now at greater risk of developing GERD? Of the remaining 20-23\% that are infected in North America, are they more likely upon cure to have a different outcome than those who have never been infected.

Much of the concern associated with whether to treat or not stems from the fact that treatment regimes have variable outcomes. While $H$. pylori is susceptible to a large variety of antimicrobials in vitro, the therapeutic activity in the gastric milieu is often nil and monotherapies have generally demonstrated poor efficacy. The most common practice is to use combinations of drugs, the so called triple or quadruple therapies containing amoxicillin, macrolides like clarithromycin, and or nitroimidazoles like metronidazole in combination with proton pump inhibitors (omeprazole) that reduce acidity and improving therapeutic action of the antimicrobials. ${ }^{16}$ Treatments can also contain bismuth salts and tetracycline. The fact that all the current therapeutic agents are old drugs and generally of broad spectrum has alarmed many who do not understand why the pharmaceutical industry has not developed novel therapeutics specifically for treating Helicobacter infections. Unfortunately, despite the obvious need, the drug industry market analyses show a rather small market and one that is disappearing-reinfection rates are so low in developed countries that patients would only be treated once and the market would eventually disappear. The need for new therapeutics is still very real for developing countries where resistance to metronidazole and macrolides renders many current therapeutics nearly useless. Unfortunately, the cost of drug development could never be recouped through sales in these markets where need is greatest. In western societies, the educational initiatives associated with efforts to reduce the wide spread practice of prescribing antibiotics have succeeded in that many physicians are reluctant to prescribe first line broad spectrum antibiotics for treatment of non-life threatening infections as $H$. pylori out of fear of contributing to drug resistance.

Animal models of infection, particularly the mouse model and Mongolian gerbil have permitted investigators to follow the course of infection and to examine 
antimicrobial efficacy and vaccine candidates. The distribution of cytokines and chemokines in the mouse model during infection has yielded much new information on mucosal inflammatory responses. Vaccine strategies using subunits of the urease have shown some promise, but often require toxin adjuvants that will likely never be used in humans. Animal studies with $H$. felis, which produces greater inflammation than $H$. pylori in the mouse model, has yielded much more information on inflammation and development of gastritis. ${ }^{17}$ Studies with other species of Helicobacter in animals implicate the microbes in other diseases including liver diseases and lower GI diseases such as inflammatory bowel disease. These models my lead to new developments in diseases other than gastritis and stomach ulcers.

The chapters that follow provide state of the art information in many areas of current interest in this exciting field. The authors accurately convey information and where controversies abound, present a balanced view. There are many areas where information is rapidly advancing in diagnostics, genomics and in disease management. There is still much to learn in areas of persistence, vaccine development, and in the basic biology of Helicobacter and its activities in the gastric mucosa. It is hoped that readers will be stimulated by historical aspects and as well become motivated by the many existing gaps in knowledge to join the many who are investigating this fascinating microbe.

\section{REFERENGES}

1. Warren J. R., and Marshall B., 1983, Unified curved bacilli on gastric epithelium in active chronic gastritis. Lancet. 1:1273-1275.

2. Dewhirst F. E., Fox J. G., and On S. L., 2000, Recommended minimal standards for describing new species of the genus Helicobacter. Int. F. Syst. Evol. Microbiol. 6:2231.

3. Loffeld R. J., Werdmuller B. F., Kusters J. G., Perez-Perez G. I., Blaser M. J., and Kuipers E. J., 2000, Colonization with cagA-positive Helicobacter pylori strains inversely associated with reflux esophagitis and Barrett's esophagus. Digestion. 62:95.

4. Scott D. R., Marcus E. A., Weeks D. L., Lee A., Melchers K., and Sachs G., 2000, Expression of the Helicobacter pylori ureI gene is required for acidic $\mathrm{pH}$ activation of cytoplasmic urease. Infect. Immun. 68:470.

5. Tomb J. F., White O., Kerlavage A. R., Clayton R. A., Sutton G. G., Fleischmann R. D., Ketchum K., Klenk H., Gill S., Dougherty B., Nelson K., Quackenbush J., Zhou L., Kirkness E., Peterson S., Loftus B., Richardson D., Dodson R., Khalak H., Glodek A., McKenney K., Fitzegerald L., Lee N., Adams M., Hickey E., Berg D., Gocayne J., Utterback T., Peterson J., Kelley J., Cotton M., Weidman J., Fujii C., Bowman C., Watthey L., Wallin E., Hayes W., Borodovsky M., Karp P., Smith H., Fraser C., and Venter J., 1997, The complete genome sequence of the gastric pathogen Helicobacter pylori. Nature 388:539-547.

6. Alm R. A., Ling L. S., Moir D. T., King B. L., Brown E. D., Doig P. C., Smith D. R., Noonan B., Guild B. C., deJonge B. L., Carmel G., Tummino P. J., Caruso A., Uria-Nickelsen M., Mills D. M., Ives G., Gibson R., Merberg D., Mills S. D., Jiang Q., Taylor D. E., Vovis G. F., and Trust T. J., 1999, Genomic-sequence comparison of two unrelated isolates of the human gastric pathogen Helicobacter. pylori. Nature 397:176-180. 
7. Chalker A. F., Minehart H. W., Hughes N. J., Koretke K. K., Lonetto M. A., Brinkman K. K., Warren P. V., Lupas A., Stanhope M. J., Brown J. R., and Hoffman P. S., 2001, Systematic identification of selective essential genes in Helicobacter pylori by genome prioritization and allelic replacement mutagenesis. F. Bacteriol. 183:1259.

8. Berg D. E., Hoffman P. S., Appelmelk B. J., and Kusters J. G., 1997, The Helicobacter pylori genome sequence: genetic factors for a long life in the gastric mucosa. Trends Microbiol. 13:468-474.

9. Marais A., Mendz G. L., Hazell S. L., and Megraud F., 1999, Metabolism and genetics of Helicobacter pylori: the genome era. Microbiol. Mol. Biol. Rev. 63:642-674.

10. Doig P., De Jonge B. L., Alm R. A., Brown E. D., Uria-Nickelsen M., Noonan B., Mills S. D., Tummino P., Carmel G., Guild B. C., Moir D. T., Vovis G. F., and Trust T. J. 1999, Helicobacter pylori physiology predicted from genomic comparison of two strains. Microbiol. Mol. Biol. Rev. 63:675.

11. Censini S., Lange C., Xiang Z., et al., $1996 \mathrm{cag}$, a pathogenicity island of Helicobacter pylori, encodes Type I-specific and disease-associated virulence factors. Proc. Natl. Acad. Sci., USA 93:14648.

12. Odenbreit S., Puls J., Sedlmaier B., Gerland E., Fischer W., and Haas R., 2000, Translocation of Helicobacter pylori CagA into gastric epithelial cells by type IV secretion. Science 287:1497.

13. Rain J.-G., Selig L., De Reuse H., Battagila V., Reverdy G., Simon S., Lenzen G., Petel F., Wojcik J., Schachter V., Chemama Y., Labigne A., and Legrain P., 2001, The protein-protein interaction map of Helicobacter. pylori. Nature 409:211.

14. Kersulyte D., Mukhopadhyay A. K., Velapatino B., Su W., Pan Z., Garcia C., Hernandez V., Valdez Y., Mistry R. S., Gilman R. H., Yuan Y., Gao H., Alarcon T., Lopez-Brea M., Balakrish Nair G., Chowdhury A., Datta S., Shirai M., Nakazawa T., Ally R., Segal I., Wong B. C., Lam S. K., Olfat F. O., Boren T., Engstrand L., Torres O., Schneider R., Thomas J. E., Czinn S., and Berg D. E., 2000, Differences in genotypes of Helicobacter pylori from different human populations. 7. Bacteriol. 182:3210.

15. Talley N. J., Vakil N., Ballard E. D., and Fennerty M. B., 1999, Absence of benefit of eradicating Helicobacter pylori in patients with nonulcer dyspepsia. N. Engl. F. Med. 341:1106.

16. de Boer W. A., and Tytgat G. N. J., 2000, Treatment of Helicobacter pylori infection. BMF. 320:31-34.

17. Lee A., O'Rourke J., de Ungria M. C., Robertson B., Daskalopoulos G., and Dixon M. F., 1997, A standardized mouse model of Helicobacter pylori infection-introducing the Sydney strain. Gastroenterology. 112:1033. 


\section{Helicobacter pylori Infection and Immunity}

